\title{
ANALISIS POTENSI PENGHEMATAN PADA PLTU UNIT 5 DENGAN AUDIT ENERGI PADA MOTOR PEMAKAIAN SENDIRI DI PT PJB MUARA KARANG
}

\author{
Supriadi Legino'), Santoso Januwarsono ${ }^{2}$, Rio Afrianda ${ }^{3)}$, \\ Teknik Elektro, Sekolah Tinggi Teknik PLN, Jakarta \\ ${ }^{1}$ supriadi@sttpln.ac.id; \\ 2 sjwarsono@gmail.com \\ ${ }^{3}$ rio.afrianda@ptpjb.com
}

\begin{abstract}
PT PJB Muara Karang power plant is an industry with a large electrical energy consumption for auxiliary power. In ISO50001 itensitas Energy Consumption (IKE) is a great need to audit energy consumption. In the contract the company's performance also set a percentage of personal use should not exceed $6 \%$ of the electricity production. Currently Posentase usage of own consumption at power plant unit 5 is greater than the power plant unit 4. It is necessary for an energy audit for the usage of its own in order to decrease the percentage of personal use in the power plant $50.5 \%$ of the current conditions and find energy savings opportunities in the power plant unit 5.

To analyze this problem using energy audits, analyzes the performance test method using "gate cycle" and testing the quality of the voltage source by using the power quality measurement analysis. Having found the equipment with the largest energy comsumtion fish bone tools used to find the main cause of this disorder.
\end{abstract}

Keywords : Auxiliary Power, Energy Audit

\begin{abstract}
Abstrak : PT PJB Muara Karang merupakan suatu industri pembangkit listrik dengan konsumsi energi listrik yang besar untuk pemakaian sendiri. Didalam ISO50001 setiap industri dengan Itensitas Kosumsi Energi (IKE) yang besar perlu dilakukan audit kosumsi energi. Pada kontrak kinerja perusahaan juga diatur prosentase pemakaian sendiri tidak boleh melebihi $6 \%$ dari produksi listrik. Saat ini Posentase konsumsi pemakaian sendiri pada PLTU unit 5 lebih besar dibandingkan PLTU unit 4. Untuk itu perlu dilakukan audit energi untuk pemakaian sendiri dengan tujuan menurunkan presentase pemakaian sendiri pada PLTU 5 sebesar $0.5 \%$ dari kondisi saat ini dan menemukan peluang penghematan energi pada PLTU unit 5.

Untuk menganalisis permasalahan ini menggunakan metode audit energi, analisis dengan metode performance test mengunakan "gate cycle" dan pengujian kualitas sumber tegangan dengan pengukuran menggunakan power quality analisis. Setelah ditemukan peralatan dengan konsumsi energi terbesar digunakan tools fish bone untuk menemukan penyebab utama kelainan ini.
\end{abstract}

Kata kunci : Pemakaian Sendiri, Audit Energi

\section{PENDAHULUAN}

Manajemen energi adalah suatu penerapan ilmu manajemen di bidang energi untuk meningkatkan efektifitas pemakaian energi oleh manusia maupun oleh industri. Manajemen energi dalam suatu industri pembangkit listrik sangat diperlukan sebagai upaya untuk meningkatkan daya saing suatu pembangkit. Selain itu dengan adanya manajemen energi di suatu pembangkit dapat meningkatkan keuntungan baik dari sektor financial maupun sektor lingkungan. Dari sektor financial dengan penerapan ilmu manajemen energi maka dengan menggunakan energi seminimal mungkin untuk memperoleh keuntungan semaksimal mungkin.

Tujuan dari penulisan ini untuk mencari peluang untuk menurunkan prosentase pemakaian sendiri hingga $0.5 \%$ dari kondisi saat ini. 
Sebagai batasan masalah pada penelitian ini dilakukan terhadap motor listrik pemakaian sendiri yang beroperasi dengan tegangan 4,16 kV.

\section{LANDASAN TEORI}

\subsection{AUDIT ENERGI}

Audit Energi adalah salah satu klausul dalam ISO 50001 tentang manajemen energi. Audit energi dapat membantu manajer energi dalam menentukan kebijakan untuk mengidentifikasi rugi-rugi (losses) energi, menghitung atau mengukur jumlah rugi-rugi energi, dan mencari peluang penghematan energi untuk menurunkan pemakaian sendiri dari suatu unit pembangkit.

Teknik Audit Energi mengevaluasi efisiensi seluruh proses peralatan/sistem yang memerlukan energi. Orang yang melakukan Audit energy di sebut auditor energi. Auditor energi memulai audit dengan megumpulkan dan mengukur penggunaan energi, menemukan semua sumber energi menuju suatu fasilitas. Kemudian auditor mengidentifikasi aliran energi setiap peralatan pengguna energi, mengukur aliran energi tersebut ke dalam fungsi diskret, mengevaluasi efisiensi setiap fungsi tersebut, dan meng- identifikasi kesempatan penghematan energi dan biaya.

Parameter yang digunakan untuk menentukan keberhasilan audit energi pada motor 4.16 kV adalah:

1) Nett Plant Heat Rate (NPHR)

$$
\begin{aligned}
& \text { NPHR } \\
& =\frac{\sum \boldsymbol{k C a l} \text { Bahan Bakar }}{\sum \boldsymbol{k W h} \times \text { Energi } \times \text { Listrik } \times \text { Netto }} \\
& N \text { NHR }=\frac{\left[\left(\text { Volume Gas mmbtu } / V_{\text {olume }} \text { BP mmbtu } \times \text { Energ i BP mscf }\right) \times 252000\right]}{(\text { Produksi Total kWh }- \text { Pemakaian Sendiri kWh })}
\end{aligned}
$$

2) Auxiliary Power

$$
\text { PS }=\frac{\text { pemakaian sendiri satu bulan }}{\text { total produksi satu bulan }}
$$

Pada suatu sistem kelistrikan pemakaian sendiri pada umumnya terdiri dari Transformator pemakaian sendiri Main Auxiliary Transformer (MAT), Switchgear 4,16 kV, SUS $416 \mathrm{~V}$, Motor Control Center (MCC), Uninterrupted PowerSupply (UPS ), Emergency Power Supply (EPS ) dan Sumber Listrik Arus Searah (DC Power Supply)

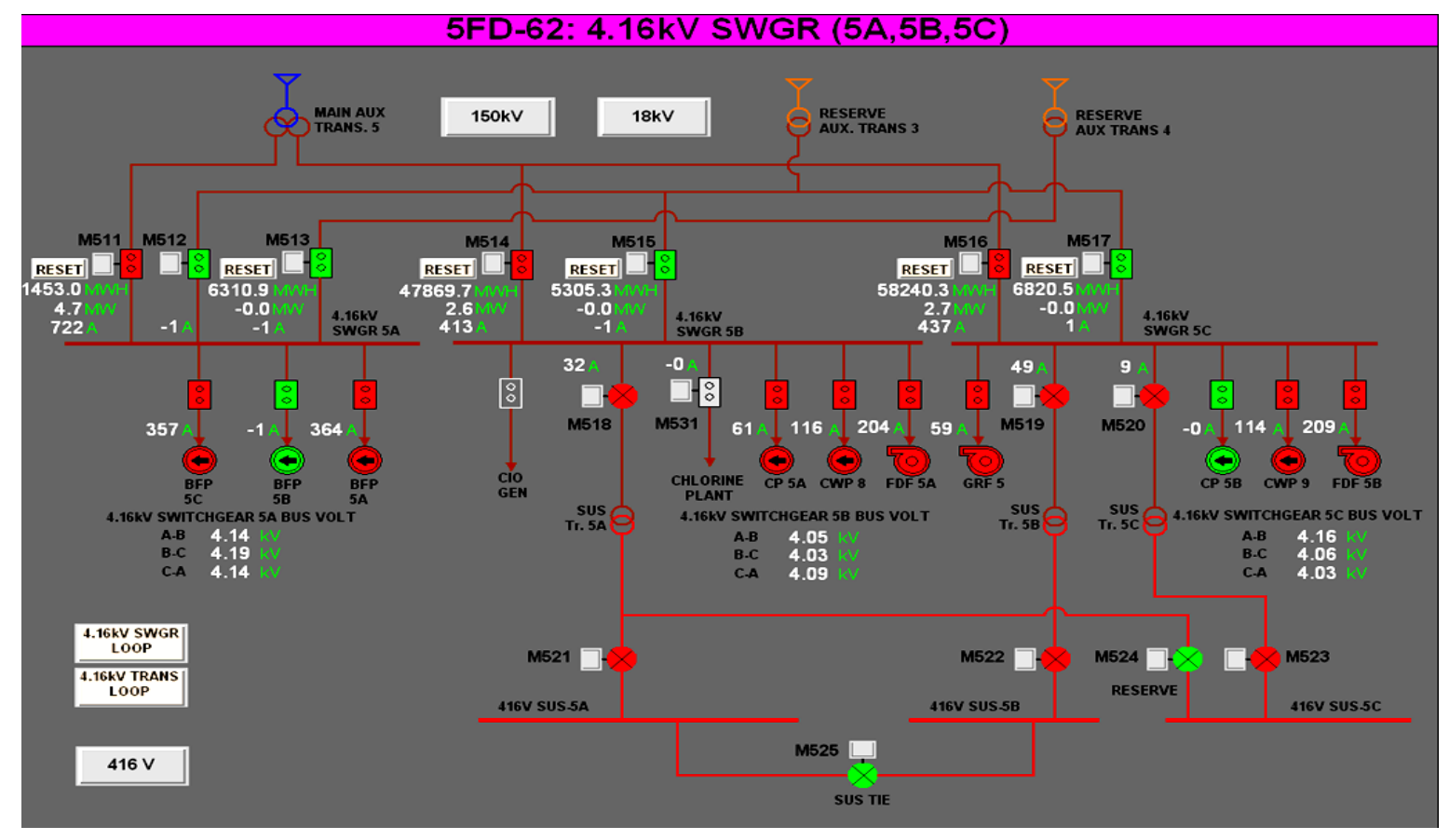

Gambar 1.1 Single Line Diagram PLTU 


\section{METODELOGI AUDIT ENERGI}

Langkah I dalam melakukan analisa potensi penghematan energi pada PLTU unit 5 menggunakan data dari pengukuran komputer DMPC, pemakaian sendiri dari PLTU 4 dibandingkan dengan data pemakaian sendiri dan PLTU 5. Kemudian dilakukan perbandingan hasil perhitungan intensitas kosumsi dari data tersebut.

Langkah II melakukan pemetaan konsumsi energi dari masing-masing unit dengan memparetokan penyumbang kosumsi energi terbesar dari masing masing unit.

Langkah III melakukan analisa penyebab besarnya kosumsi energi dari peralatan yang telah dipetakan, dengan membandingkan ke standar, data komisioning atau data performa terbaik.

Langkah IV menganalisa pola operasi terbaik untuk peralatan-peralatan dengan kapasitas penyerapan energi besar agar dapat lebih di optimalkan.

Langkah V Melakukan pengukuran setelelah dilakukan tindak lanjut dari temuan diatas untuk melihat keberhasilan dari tindak lanjut diatas dan kembali dianalisa.

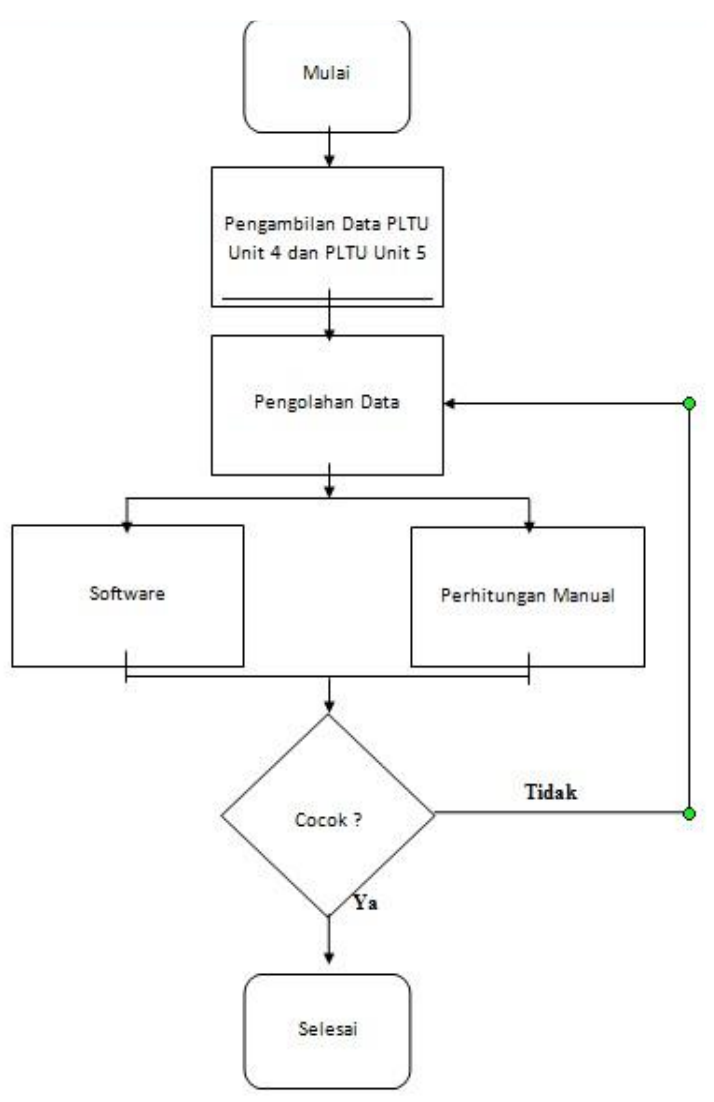

\section{ANALISA DAN PEMBAHASAN}

Kosumsi energi listrik pada peralatan di suatu unit pembangkit selalu di monitor untuk mengetahui kosumsi dari tiap-tiap peralatan dengan tujuan apabila terjadi kejanggalan pada kosumsi suatu peralatan pada pembangkit dapat diketahui sejak dini sehingga dapat dilakukan penanganan secara cepat dan tepat. Seperti pada Tabel 4.1, Terlihat terdapat selisih yang cukup besar pada pemakaian sendiri antara PLTU 4 dan PLTU 5, Sehingga pada kondisi ini PLTU 5 lebih boros penggunaan energi hingga $258.700 \mathrm{KWH}$ pada bulan Januari 2016, atau jika dihitung dalam rupiah senilai Rp.336.310.000,- lebih boros dari unit 4.

Tabel 4.1 Tabel Pemakaian Sendiri 2016

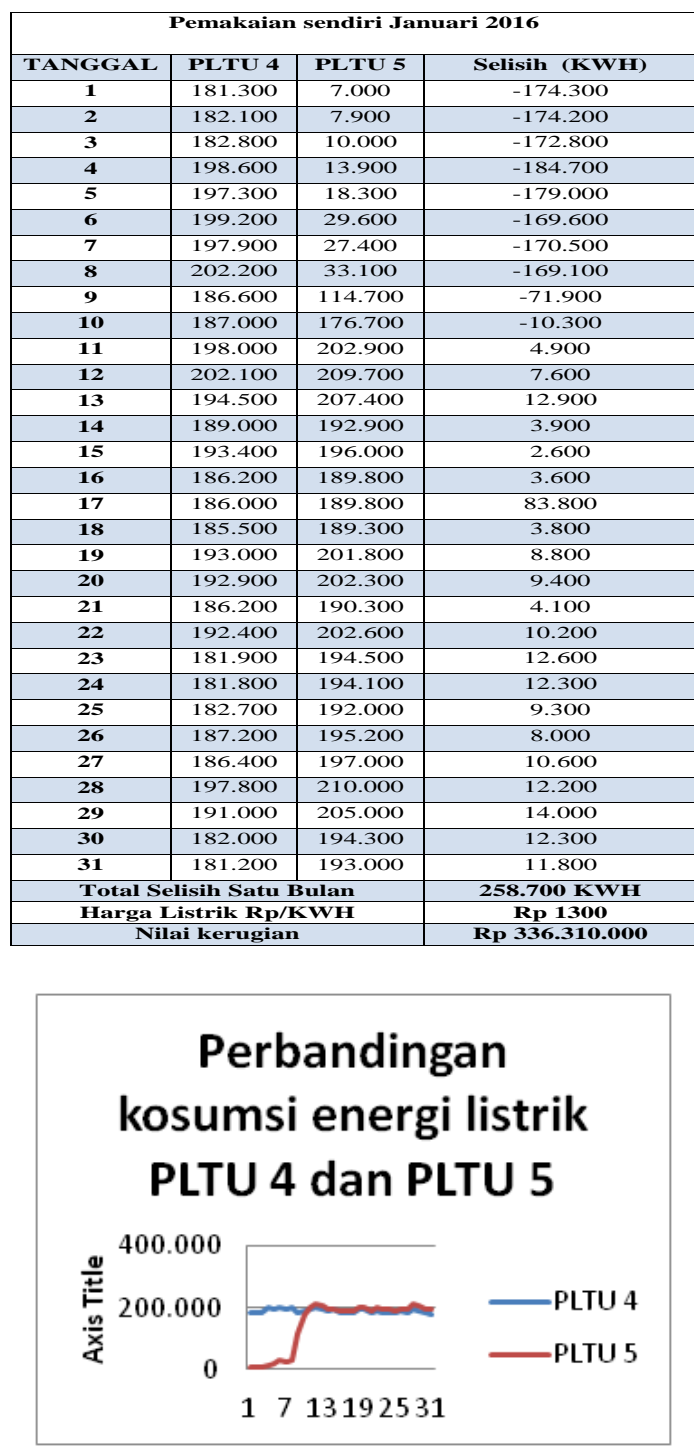

Gambar 4.1 Selisih NPHR PLTU 4 dan 5 


\subsection{Analisis Kosumsi Energi Pada PLTU 4 dan PLTU 5}

Dari data pengukuran di PLTU 4 dan PLTU 5 pada saat beban yang sama untuk beban-beban mulai dari tegangan 4160 Volt hingga 380 untuk mengetahui performa masing masing peralatan, dengan cara membandingkan performa saat ini dengan performa saat komisioning. Dengan menggunakan persamaan:

$$
P=\sqrt{3} \times V \times I \times \cos \theta
$$

Tabel 4.2 Tabel Pengukuran SWGR 4

\begin{tabular}{|c|c|c|r|}
\hline \multicolumn{4}{|c|}{ SWGR PLTU 4 } \\
\hline \multirow{2}{*}{ Peralatan } & P act & P ref & \multicolumn{1}{|c|}{ P loss } \\
\cline { 2 - 4 } & \multicolumn{3}{|c|}{ Watt } \\
\hline BFP 4A & - & - & - \\
\hline BFP 4A & 2.019 .896 & 2.013 .402 & 6.494 .8 \\
\hline BFP 4A & 2.045 .876 & 2.019 .896 & 25.979 .4 \\
\hline CP 4A & 280.378 & 280.378 & 0 \\
\hline CP 4B & - & - & - \\
\hline CWP 5 & 634.122 & 634.122 & 0.1 \\
\hline CWP 6 & 660.713 & 655.531 & 5.181 .7 \\
\hline CWP 7 & - & - & - \\
\hline FDF 4A & 1.053 .819 & 1.053 .819 & 0 \\
\hline FDF 4B & 1.012 .706 & 1.012 .706 & 0 \\
\hline GRF & 253.150 & 250.100 & 3.050 \\
\hline Total & $\mathbf{7 . 9 6 0 . 6 6 3}$ & $\mathbf{7 . 9 1 9 . 9 5 7}$ & $\mathbf{4 0 . 7 0 6}$ \\
\hline
\end{tabular}

Tabel 4.3 Tabel Pengukuran SWGR 5

\begin{tabular}{|c|c|c|c|}
\hline \multirow{4}{*}{ SWWGR PLTU 5 } \\
\hline \multirow{2}{*}{ BFP 4A } & P act & P ref & P loss \\
\cline { 2 - 4 } & \multicolumn{3}{|c|}{ Watt } \\
\hline BFP 4A & 2.135 .752 & 2.135 .753 & - \\
\hline BFP 4A & 2.242 .965 & 2.138 .196 & 104.773 \\
\hline CP 4A & 300.314 & 290.168 & 10.145 \\
\hline CP 4B & - & - & - \\
\hline CWP 5 & 651.971 & 648.398 & 3.581 \\
\hline CWP 6 & 637.012 & 635.748 & 1.264 \\
\hline CWP 7 & - & - & - \\
\hline FDF 4A & 1.070 .351 & 1.072 .505 & -2.153 \\
\hline FDF 4B & 1.040 .091 & 1.041 .153 & -1.061 \\
\hline GRF & 381.402 & 381.403 & -0.5 \\
\hline Total & $\mathbf{8 . 4 5 9 . 8 6 5}$ & $\mathbf{8 . 3 4 3 . 3 1 6}$ & $\mathbf{1 1 6 . 5 4 8}$ \\
\hline
\end{tabular}

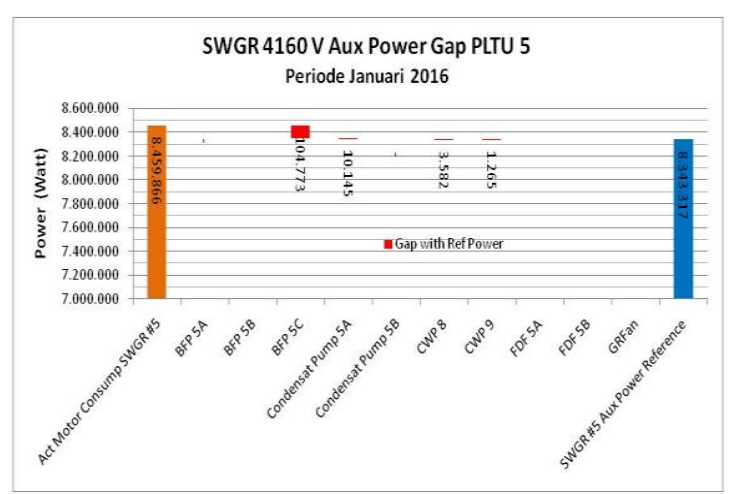

Gambar 4.2 Pareto SWGR 4160 Volt PLTU 4

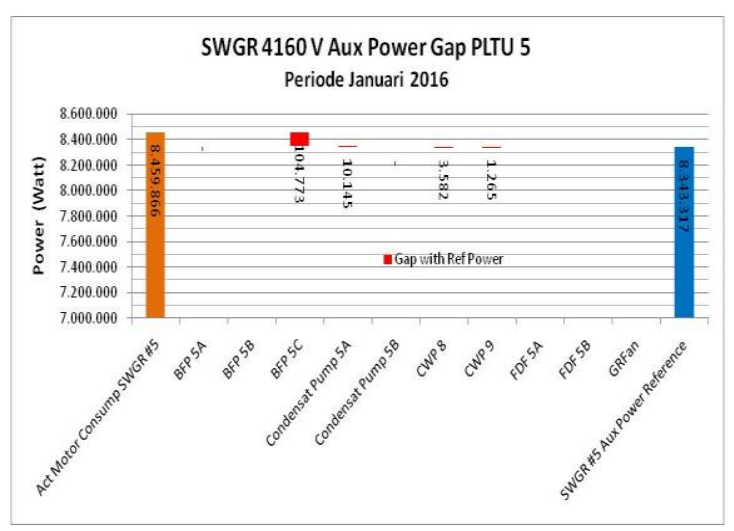

Gambar 4.3 Pareto SWGR 4160 Volt PLTU 5

Dari review terhadap power gap motor motor peralatan auxiliary PLTU 4 dan PLTU 5 dengan power reference terhadap data komisioning diketahui beberapa peralatan yang mempunyai gap power cukup besar sebagai berikut

Tabel 4.4 Tabel Nilai Kerugian dari unit 4

\begin{tabular}{|l|c|c|lc|}
\hline PERALATAN & KWH & RP/KWH & \multicolumn{2}{|c|}{$\begin{array}{l}\text { KERUGIAN } \\
\text { (RP/JAM) }\end{array}$} \\
\hline BFP 4C & 621,6 & 1300 & Rp & $\mathbf{8 0 8 , 0 8 0}$ \\
\hline BFP 4B & 153,6 & 1300 & Rp. & 199,680 \\
\hline ACWP 4B & 79,2 & 1300 & Rp. & 102,960 \\
\hline CWP 6 & 122,4 & 1300 & Rp. & 159,120 \\
\hline ISAF 4A & 45,6 & 1300 & Rp. & 59,280 \\
\hline \multicolumn{2}{|c|}{ TOTAL LOSSES PER HARI } & \multicolumn{2}{l|}{ Rp.1.329.120 } \\
\hline
\end{tabular}

Tabel 4.5 Tabel Nilai Kerugian dari unit 5

\begin{tabular}{|l|c|c|lr|}
\hline PERALATAN & KWH & RP/KWH & \multicolumn{2}{|c|}{$\begin{array}{c}\text { KERUGIAN } \\
\text { (RP/JAM) }\end{array}$} \\
\hline BFP 5C & 6,017 & 1300 & Rp. 7.821 .840 \\
\hline CP 5A & 242,4 & 1300 & Rp & 315.120 \\
\hline CWP 8 & 84 & 1300 & Rp & 109.200 \\
\hline CWP 9 & 28,8 & 1300 & Rp & 37.440 \\
\hline ACWP 5A & 16,8 & 1300 & Rp & 21.840 \\
\hline \multicolumn{2}{|r|}{ TOTAL LOSSES PER HARI } & \multicolumn{2}{l|}{ Rp. 8.305 .440} \\
\hline
\end{tabular}


Setelah dilakukan audit dan mendata kosumsi energi pada motor, dilakukan perhitungan besarnya losses untuk motormotor seperti pada tabel 4.4 dan 4.5 dengan losses paling besar dibandingkan data komisioning. Dari hasil pengukuran dan perhitungan di atas, dapat kita lihat bahwa PLTU 4 lebih boros Rp.1.329.120,per hari dan PLTU 5 lebih boros Rp.8.305.440,- perhari, Atau PLTU 5 lebih boros Rp.6.976.320,- perhari.

\subsection{Analisis Performance Test PLTU 4 dan 5}

Untuk mengetahui performa dari PLTU 4 dan PLTU 5 dilaksanakan performance test dengan mengambil data pada saat dan beban yang sama lalu di bandingkan dengan data hasil pengukuran pada beberapa bulan terakir dan saat komisioning. Data yang di ambil pada saat performance test akan di olah menggunakan soft ware gate cycle untuk di ketahui hasil dan performa suatu unit pembangkit.

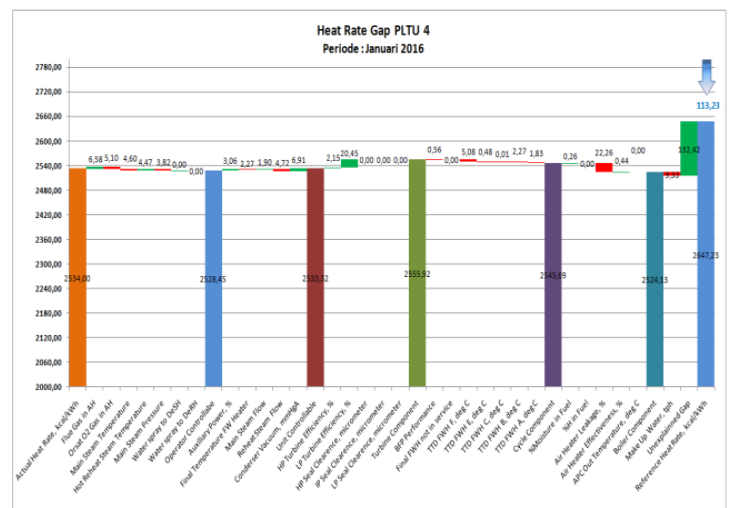

Gambar 4.4 Pareto Hasil Performance Test PLTU 4

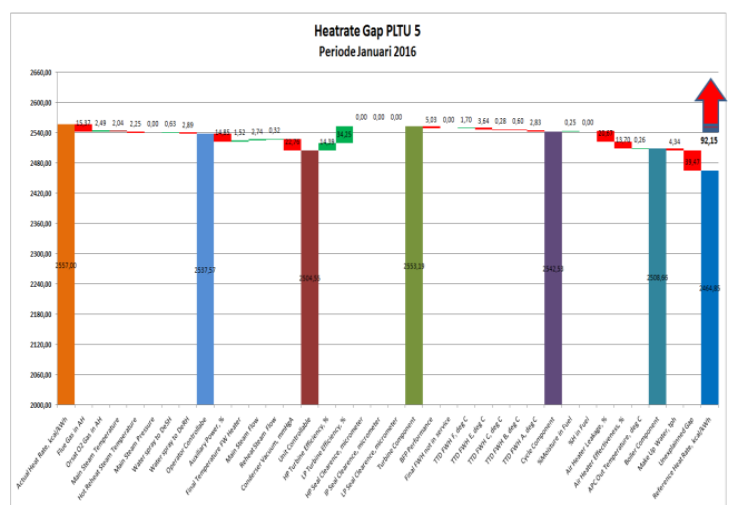

Gambar 4.5 Pareto Hasil Performance Test PLTU 5

\subsection{Analisis Menggunakan Power Quality Analysis}

Untuk mengetahui kinerja masingmasing motor PT PJB Bekerjasama dengan Pihak ketiga untuk melakukan pengukuran. dengan melakukan pengukuran motor-motor dengan alat Power Quality Analizer.
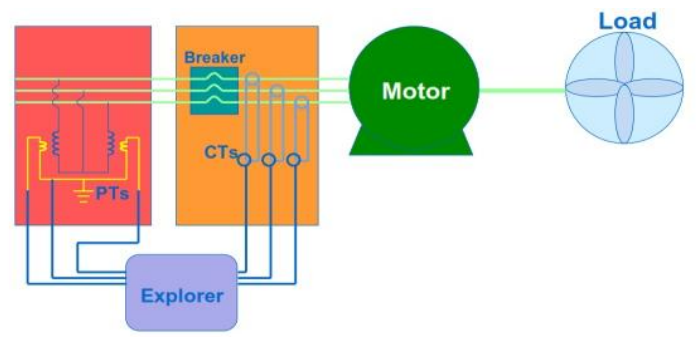

\section{Gambar 4.6 Cara Pemasangan Power Quality Analysis}

Tabel 4.6 Tabel Hasil Pengukuran menggunakan Power Quality Analysis

\begin{tabular}{|c|c|c|c|}
\hline No. & Motor ID & $\begin{array}{l}\text { Power } \\
\text { Quality }\end{array}$ & $\begin{array}{c}\text { Current } \\
\text { Unbalance }\end{array}$ \\
\hline 1 & BFP $4 A$ & Pass & Pass \\
\hline 2 & BFP $4 B$ & Pass & Pass \\
\hline 3 & BFP 4 C & Pass & Pass \\
\hline 4 & CP $4 A$ & Pass & Pass \\
\hline 5 & CP 4B & Pass & Pass \\
\hline 6 & CWP 6 & Pass & Pass \\
\hline 7 & CWP 7 & Pass & Pass \\
\hline 8 & FDF $4 A$ & Pass & Pass \\
\hline 9 & FDF $4 B$ & Pass & Pass \\
\hline 10 & Gas Recirculation Fan 4 & Pass & Pass \\
\hline 11 & BFP 5 A & Pass & Pass \\
\hline 12 & BFP 5B & Pass & Pass \\
\hline 13 & BFP 5C & Pass & Pass \\
\hline 14 & CP $5 A$ & Pass & Pass \\
\hline 15 & CP $5 \mathrm{~B}$ & Pass & Pass \\
\hline 16 & CWP 8 & Pass & Pass \\
\hline 17 & CWP 9 & Pass & Pass \\
\hline 18 & FDF $5 A$ & Pass & Pass \\
\hline 19 & FDF $5 B$ & Pass & Pass \\
\hline 20 & Gas Recirculation Fan 5 & Pass & Pass \\
\hline
\end{tabular}

\subsection{Analisis Akar Masalah Dengan Fish Bone Diagram}

Untuk menemukan akar permasalahan dari tingginya penyerapan energi listrik dari PLTU 5 dibuat fish bone diagram untuk mempermudah dalam menemukan akar permasalahan. 


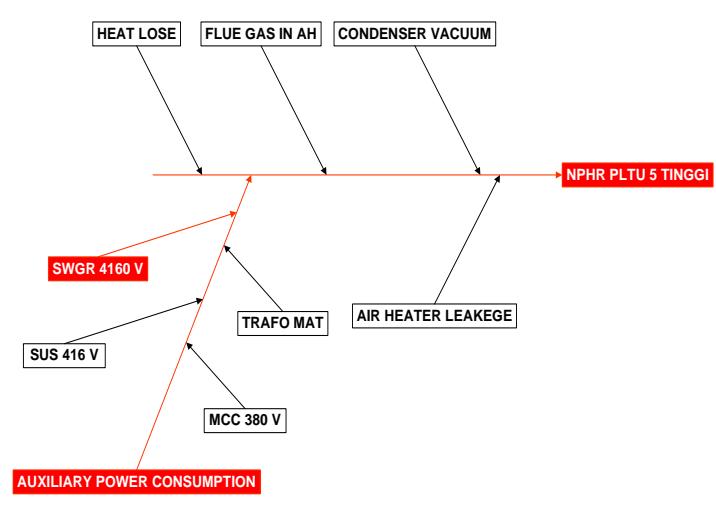

Gambar 4.7 Fish Bone NPHR

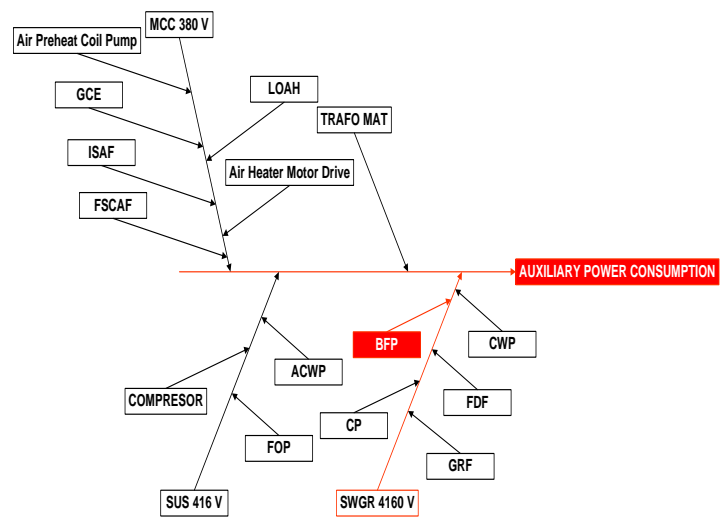

Gambar 4.8 Fish Bone Auxiliary Power

Dari hasil analisa menggunakan fish bone di dapatkan penyumbang tingginya berasal dari SWGR 4160 Volt, dan apabila di lakukan penarikan akar permasalahan selanjutnya di dapatkan permaslahan besarnya kosumsi pemakaian energi listrik pada SWGR 4160 Volt berasal dari BFP 5B yang di sebebkan oleh leakstrough pada valve sirkulasi yang menyebabkan BFP bekerja lebih berat untuk memompakan air menuju drum, karena sebagian air yang di pompakan menuju drum kembali ke deaerator levat kebocoran pada Valve siskulasi.

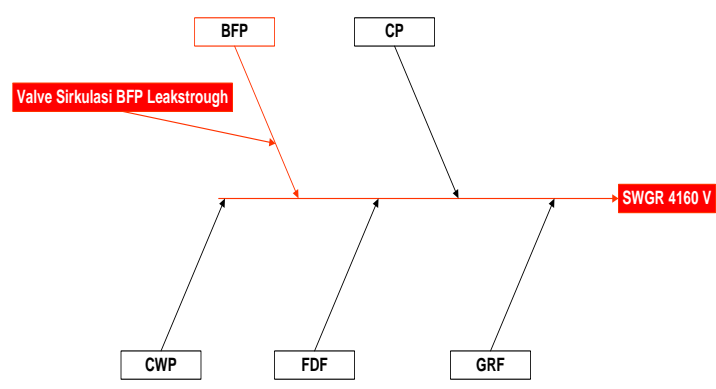

Gambar 4.9 Fish Bone SWGR 4160 Volt

\subsection{Analisis Nilai Penghematan Energi}

Dengan mengambil peluang di atas dapat di lakukan pengematan sebesar $266.46 \mathrm{KW}$ per jam atau 6.3 MW per hari. Dan dapat menurunkan pemakaian sendiri sebesar $0.29 \%$ dari $5.82 \%$ menjadi 5.53 $\%$

$$
\begin{aligned}
\text { PS }= & \frac{\text { pemakaian sendiri satu bulan }-(6.3 \mathrm{MW} \times 23 \text { hari })}{\text { total produksi satu bulan }} \times 100 \% \\
& \text { Pemakaian Sendiri }=\frac{2921.7-(6.3 \times 23 \text { hari })}{50.193 .3 \mathrm{MW}} \times 100 \%
\end{aligned}
$$

Pemakaian Sendiri $=5.53 \%$

\section{GRAFIK PEMAKAIAN SENDIRI SETELAH...}

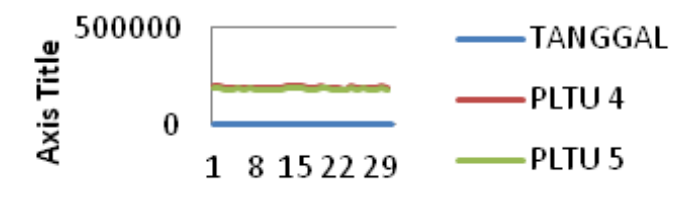

Gambar 4.10 Grafik Pemakaian Sendiri Setelah dilakukan Audit

\section{KESIMPULAN}

1. Dari penelitian di atas di dapatkan yang menjadi penyebab terbesar tingginya prosentase pemakaian sendiri dari PLTU 5 berasal dari BFP $5 \mathrm{C}$.

2. BFP $5 \mathrm{C}$ yang menyumbang sekitar $250 \mathrm{KW}$ lebih boros setiap jam atau lebih boros $0.29 \%$ dari seharusnya, yang disebabkan oleh kebocoran pada valve sirkulasi dan mengakibatkan beban kerja dari BFP menjadi lebih besar.

3. Salah satu penyebab tingginya NPHR pada PLTU 5 karena nilai vakum kondenser sebesar $690 \mathrm{mmHg}$. Disebebkan banyak menghisap lumpur/kotoran. 


\section{DAFTAR PUSTAKA}

1. Appiarius, J. C.(1983). Electric Utility System And Practice. Edited by Homer M. Rustebakke. New York: John Wiley \& Sons,.

2. Cengel, Y. A. and Michael A. Boles. (1989). Thermodinamics: An Enginering Approach. Singapore : McGraw- Hill.

3. Eastop, T. D. and D. R. Croft. (1990). Energy Efficiency. Harlow : Longman.

4. El-Wakil, M.M.(1984).Power Plant Technology. New York: Butterworths.
5. Almanda Deni.(1999). Cogeneration Pembangkit Listrik yang Ideal, FT UGM, Yogyakarta.

6. Miller, R. $H$. and James $H$. Malinowski. (1994). Power System Operation. Singapore: McGraw-Hill International Editions.

7. Reynolds, W. C. and Henry C. Perkins. (1977). Enginering Thermodynamics. Translated by Filino Harahap. Jakarta: Penerbit Erlangga. 